\title{
REVIEW OF THE BOOK
}

\section{The History of the Theory of Structures: Searching for Equilibrium by KARL-EUGEN KURRER}

\author{
Marcílio Alves ${ }^{\mathrm{a}^{*}}$ \\ a Grupo de Mecânica dos Sólidos e impacto em Estruturas. Universidade de São Paulo - USP, São Paulo, SP, Brasil. E-mail: maralves@usp.br \\ *Corresponding author
}

http://dx.doi.org/10.1590/1679-78255470

History puts knowledge in perspective (Alves, 2018). This could not be more true when one is faced with the monumental work of Karl-Eugen Kurrer, The History of the Theory of Structures: Searching for Equilibrium (Kurrer, 2018), whose cover is shown in Figure 1.

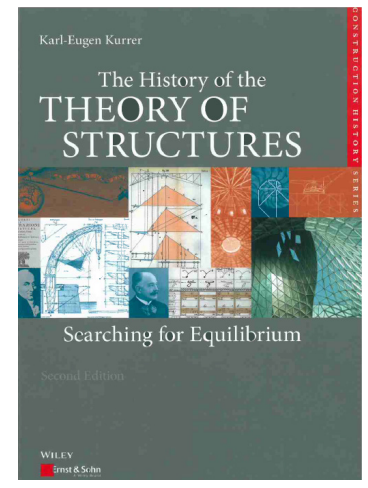

Figure 1: Cover of the book reviewed here.

Beautifully illustrated, with and excellent production, drawings, typesetting and typo design, this English second edition translated from the original german by Phillip Thrift critically presents, with over 1000 illustrations, the development of the theory of structures from a historical perspective.

As stated in the Foreword by Ekkehard Ramm, "it is no longer the calculation process and method issues, but rather principles, modelling, realism, quality assurance and many other aspects that form the focus of our attention". Indeed, the engineer working, teaching, researching in the field of structures is here rest assured that his/her effort and commitment towards these activities can have profound consequences in a vast area of the human effort towards safety, functionality and aesthetic of structures. These later aspects underpin the various discoveries made in history by brilliant minds.

The author of this book sees the history of the structures and their analyses as divided in four periods: the preparatory one, from 1575-1825, followed by the discipline-formation period, between 1825-1900, the consolidation period, 1900-1950, and the integration period 1950-to date, including an innovation phase from 1950 to 1975. It is along this classification that the book has its thread, with the author dividing it in 14 chapters plus one dedicated to the biographies of 260 protagonists of the theory of structures.

The author claims that "... attempts to introduce formal teaching into theory of structures fail because the knowledge about its historical development is not adequate to define the real object of theory of structures".

Although not being possible to describe section by section here, some parts of the book strikes one in a way or in another. For instance, the author presents in Chapter 2 the tetrahedron of the four realms and of the beauty and law in architecture, reproduced in Figure 2. It indicates to this writer the deepness achieved by the book author in structuring his thoughts in a clear way, product of the adventure that the knowledge of structure analysis and conception is. It is 
also evoked in Chapter 3 as a tetrahedron of engineering sciences: "relationship between knowledge, products (methods) and the market (society) on the one hand and the elementary activities of cognition, design and answerability on the other hand with the innovation process of invention, innovation and diffusion (by the economist Joseph Alois Schummpeter)".
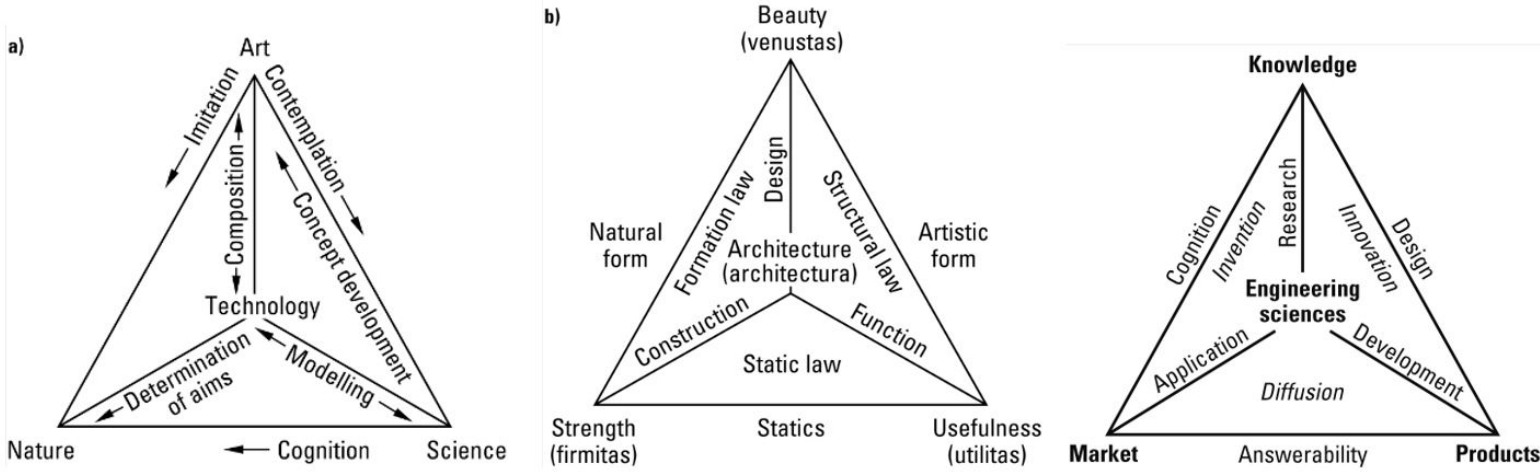

Figure 2: Tetrahedron exposing the various relationships between branches of human activity.

In Chapter 2 one finds what is a landmark of the book: examples, figures, documents and "cases". One of the passages comments on the Garabit Viaduct, designed by G. Eifel, the engineer who designed and lent his name to the tower in Paris. I use it to bring to the reader another two examples of bridges which could well be cited in this book: Ponte Hercílio Luz (designed by Robinson e Steinman, see H. Carvalho et al., 2017), in Florianópolis and Ponte Maria Pia (designed by Eiffel and Théophile Seyrig), in Porto, Figure 3. 

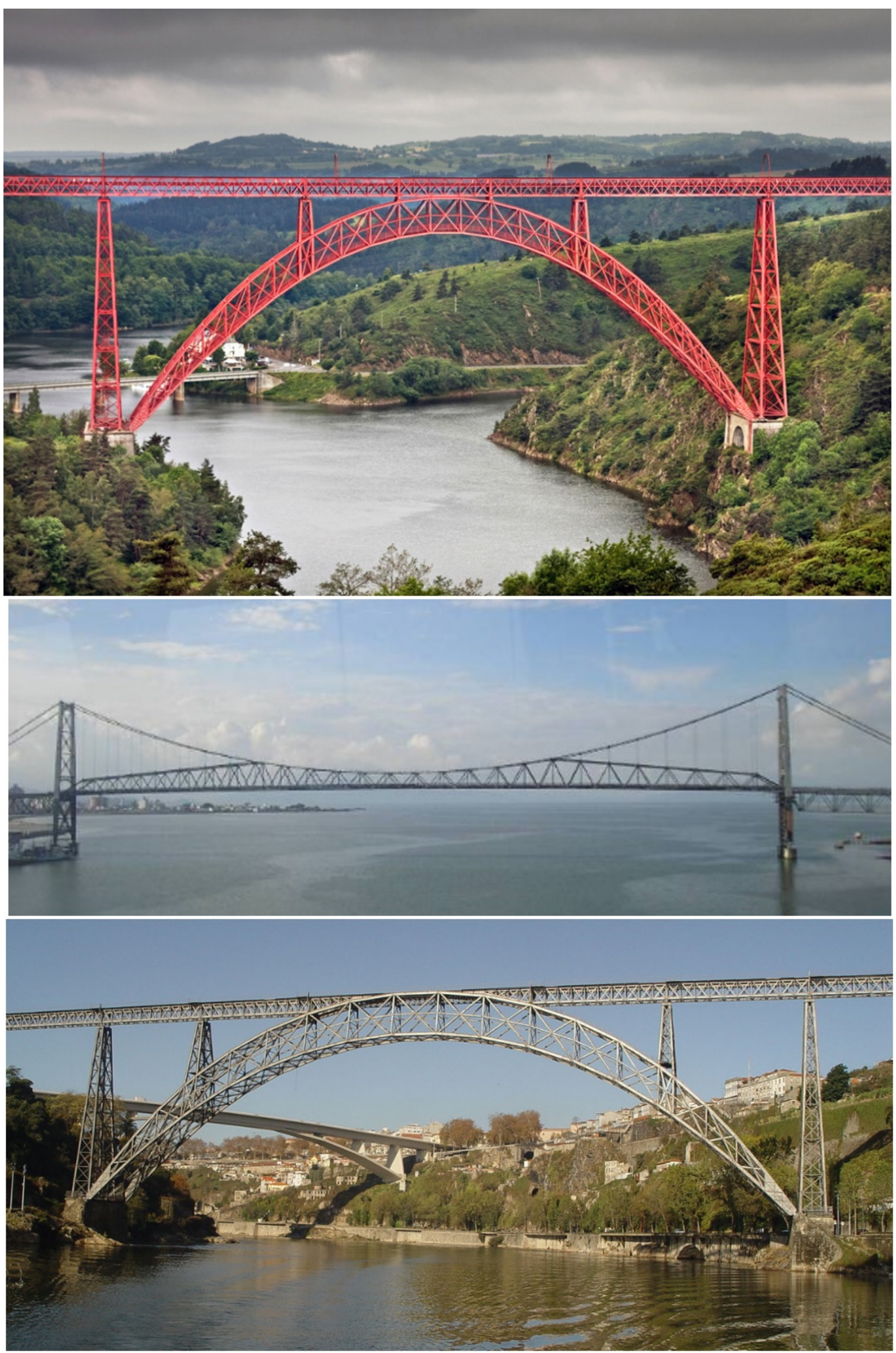

Figure 3: The Garabit Viaduct (G. Eiffel), Ponte Hercílio Luz (Robinson and Steinman), Ponte Maria Pia (G. Eiffel and T. Seyrig). 
Chapter 3 is devoted to the disciplines of theory of structures and applied mechanics, including an account on the born of the engineering handbooks, the main ones being described. In engineering sciences one "generates new knowledge through research, create new products and methods through development and support the marketability of new products and methods through application". Thoughts like this are not that common in the daily teaching of structures and in part they are "captured" only by those minds that have this "perspective of knowledge" pointed out in the opening of this text and that is cultivated among the ones who study the subject of history.

Chapter 4 is on Arches, while the history of earth pressure theory is explored at length in Chapter 5. Its main application in the past was the design of the retaining walls in fortifications and this chapter is nearly a book on its own. The author states here that the "earth pressure theory was the first genuine engineering science theory that shaped the scientific self conception of modern civil engineering ... and not (the) beam theory".

It is worth, if to put Chapter 6, "The beginnings of a theory of structures", in a nutshell, to quote the author that “... the final piece in the beam theory jigsaw, which Galileo had begun, was inserted by Charles Augustin Coulomb in 1773 , for a long time it remained only one of many beam analysis hypothesis. Not until 1826 did Navier puts together statics and strength of materials to form theory of structures. And that is where the history of theory of structures, in its narrower sense, really begins."

One is really amazed to see drawings like the stress-strain curve of a cast iron and a copy of the da Vinci's drawings, reproduced in Figure 4.
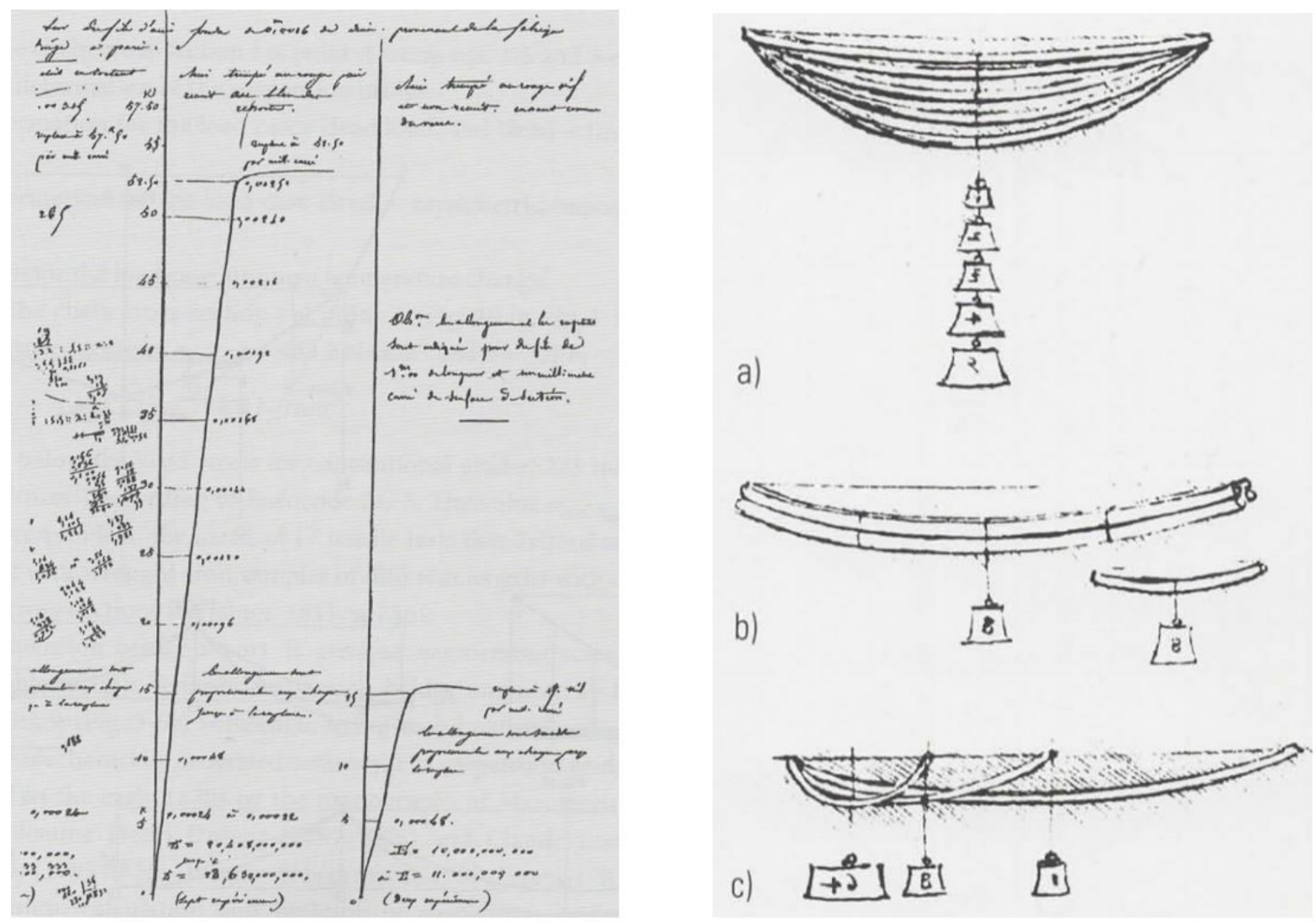

Figure 4: Early tensile test experiments and studies of da Vinci on beams.

Chapter 6 has an interesting section on strength of materials. The author argues that "What was needed ... was neither a geometrical theory of proportions ... nor a static proportions theory ... but rather the unity of strength test ..." and with that the field of strength of materials is introduced. It is with great admiration that one encounters these various instruments in Figure 5 used to measure material properties. 


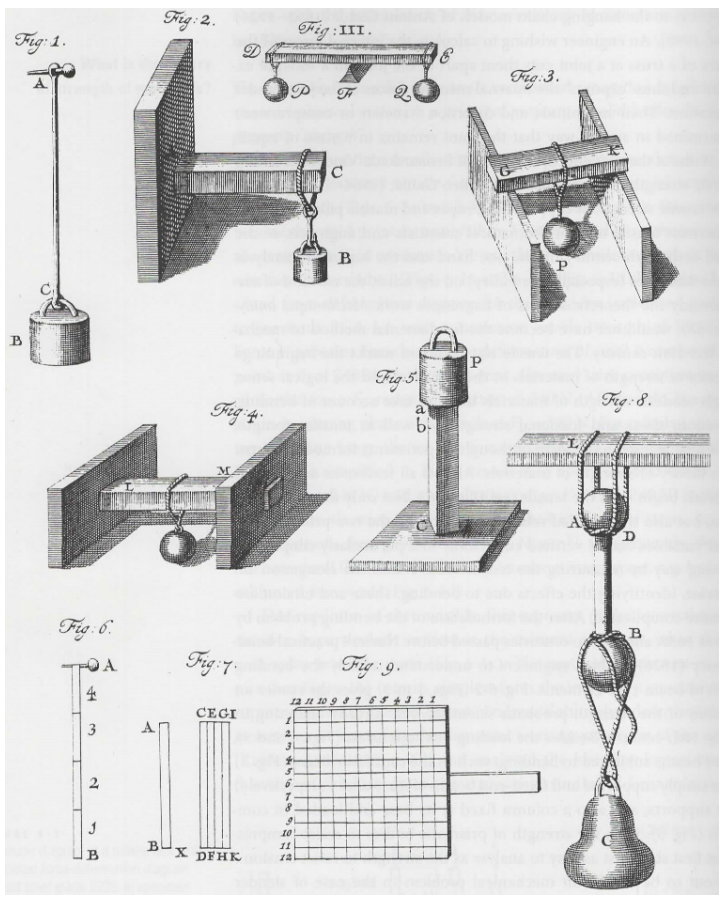

Figure 5: Various instruments for material testing.

The author remarks that "The tensile test marks the beginning of a theory of strength of materials" and further that " ... the tensile test can reveal the internal tensile resistance at every stage ... by way of a calibrated force scale ... The rendition of the invisible, this exposure of the internal tensile resistance, is particularly evident at the moment of failure ...". This made me to remember da Vinci's conception of force to which he says "Force is the death of motion" (Ucelli, 1939).

Of course, one can not let aside the contribution of Galileo Galilei, already implied in his thought experiment of the tensile test and of the beam bending, illustrated in Figure 6.
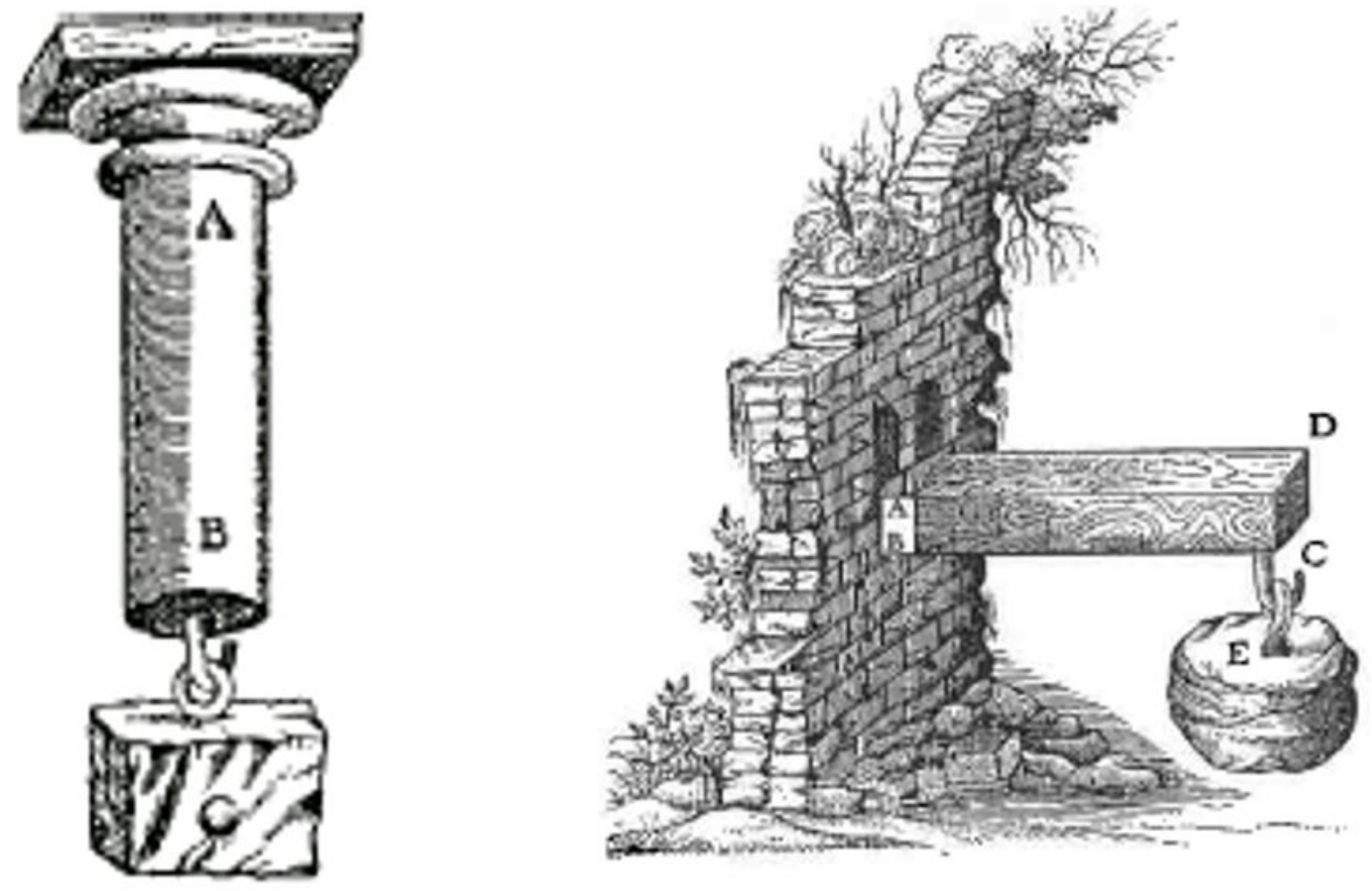

Figura 6: Thought experiments of Galileo. 
This chapter 6 gives also a good account of the Petrus von Musschenbroek's (1692-1761) apparatus for material testing. He measured the strength of copper, brass, silver, gold, iron, steel, lead using machines like the ones in Figure 7. One learns that, as a Dutch professor of physics at Utrecht and Leiden, he was the first person to build an apparatus for tensile tests and also for testing buckling, determining well before Euler that the buckling load is inversely proportional to the square of the length of the member.
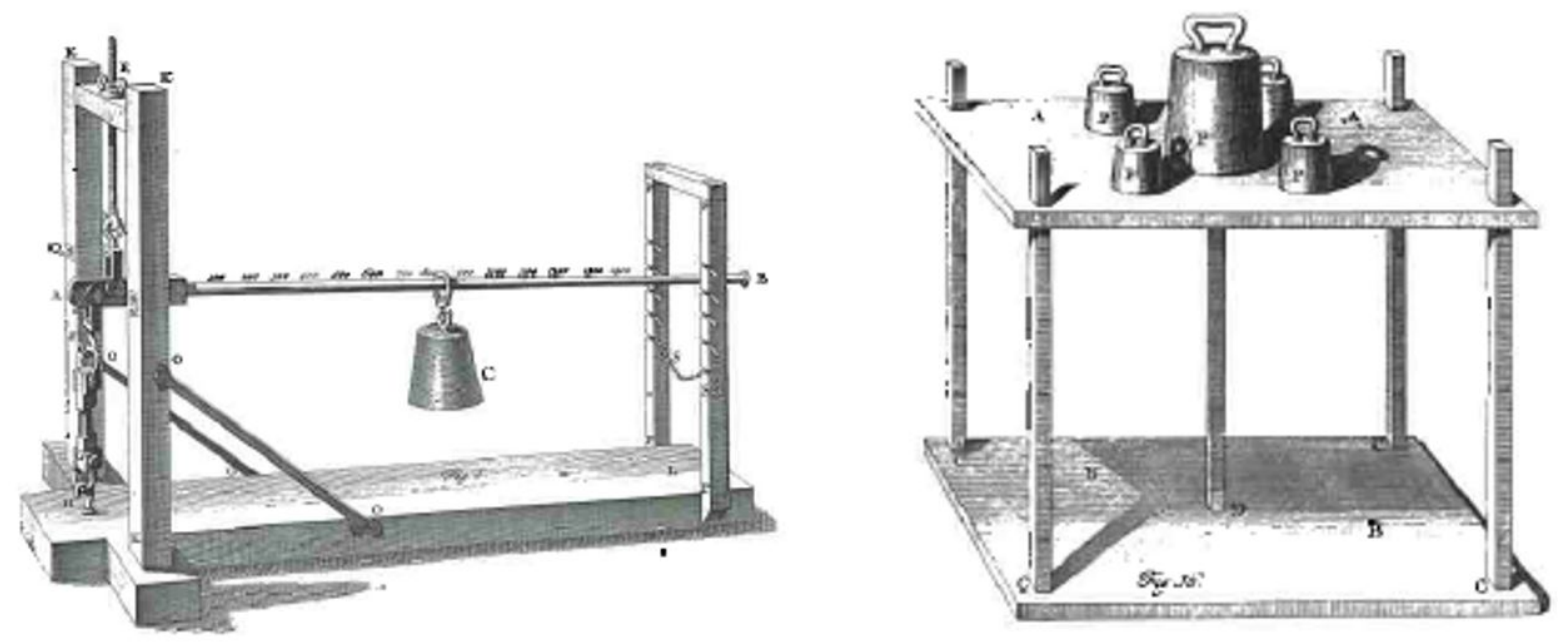

Figure 7: Early design of tensile test machine and measurement of the buckling load.

Also, it was P.S. Girard who wrote the first book dedicated to the theory of strength of materials Traite analytique de la résistance des solid in 1798, including an account of the history of this subject since Galileo. Coulomb completed the theory of beams in his Memoirs in 1773-1776. Franz Joseph Ritter von Gerstner (1756-1832) is also discussed here. He analysed arches, beams, inclined pin-jointed bar, three pin system, etc. But it was Claude-Louis-Marie-Henri Navier (1785-1836) who can be considered, according to the author, the father of the modern theory of structures.

Chapter 7 is about the discipline-formation period and strikes out to learn about the les polytechniciens and the military character the École Polytechnique assumed when Napoleon was in power. It is made clear by the author the importance of the Polytechnique engineers for the military conquers of Napoleon. This École was even dissolved in 1816 and reopened one year later. It is also interesting to learn that it was J.W. Schwedler (1823-1894) who first presented the differential equations for beam equilibrium.

One encounters in this book chapter 7 Carlo Alberto Pio Castigliano (1847-1884), with his Théorie de l'Équilibre des Systèmes Élastiques et ses Applications, published in 1879. Side by side with Maxwell and Mohr, Castigliano was responsible for the law of energy conservation for structural mechanics, which form the basis of our current method of analyses. It is the application of the energy conservation principles that lead Lord Rayleigh, in his Theory of Sound, to obtain the natural frequency of an elastic body.

Chapter 8 delves in the modern structural steelwork. There one finds the origins of the torsion theory in iron construction and the theory developed by Saint-Venant. It is also contemplated here the surge of cranes, with the first electrically driven crane designed by Rudolf Bredt (1842-1900) whose cooperation to torsion theory is also emphasized. The chapter also comments on the shear centre as well as on composite structures made in reinforced concrete.

It is in Chapter 9 that spatial frameworks are explored. One learns here on the early phase of the 3D structural analyses, with the books by August Ferdinand Möbius (1790-1868) and Otto Mohr (1835-1918), which the author claims attracted little interest from practising structural engineers. It is indeed interesting to learn here that it was Wilhelm Schwedler (1823-1894) who really became the first engineer to make the transition to a dome working in three dimensions, the Schwedler dome. An interesting fact is that in the Schwedler's first attempt of building such a structure it simply collapsed while being built. It was rebuilt one year later again by him and with success, a lesson that teaches us that some initial failure in a design can be used for learning how to correct the flaws.

It goes a long series of comments on August Föppl who authored the first monograph on spatial frameworks in 1892. Curious also that the first prefabricated spatial framework was designed by Alexander Graham Bell in 1907. It was made by small tetrahedra and comments are given to the geodesic dome, as the ones designed by Richard Buckminster Fuller (1895-1983). 
Here, I felt that the Olympia Park, in Munique, could be presented as good examples of shell-like 3D structure. Likewise, a mention to the Goetheanum, in Dornach, as a magnificent building on reinforced concrete could be cited in Chapter 10. They are depicted in Figure 8.
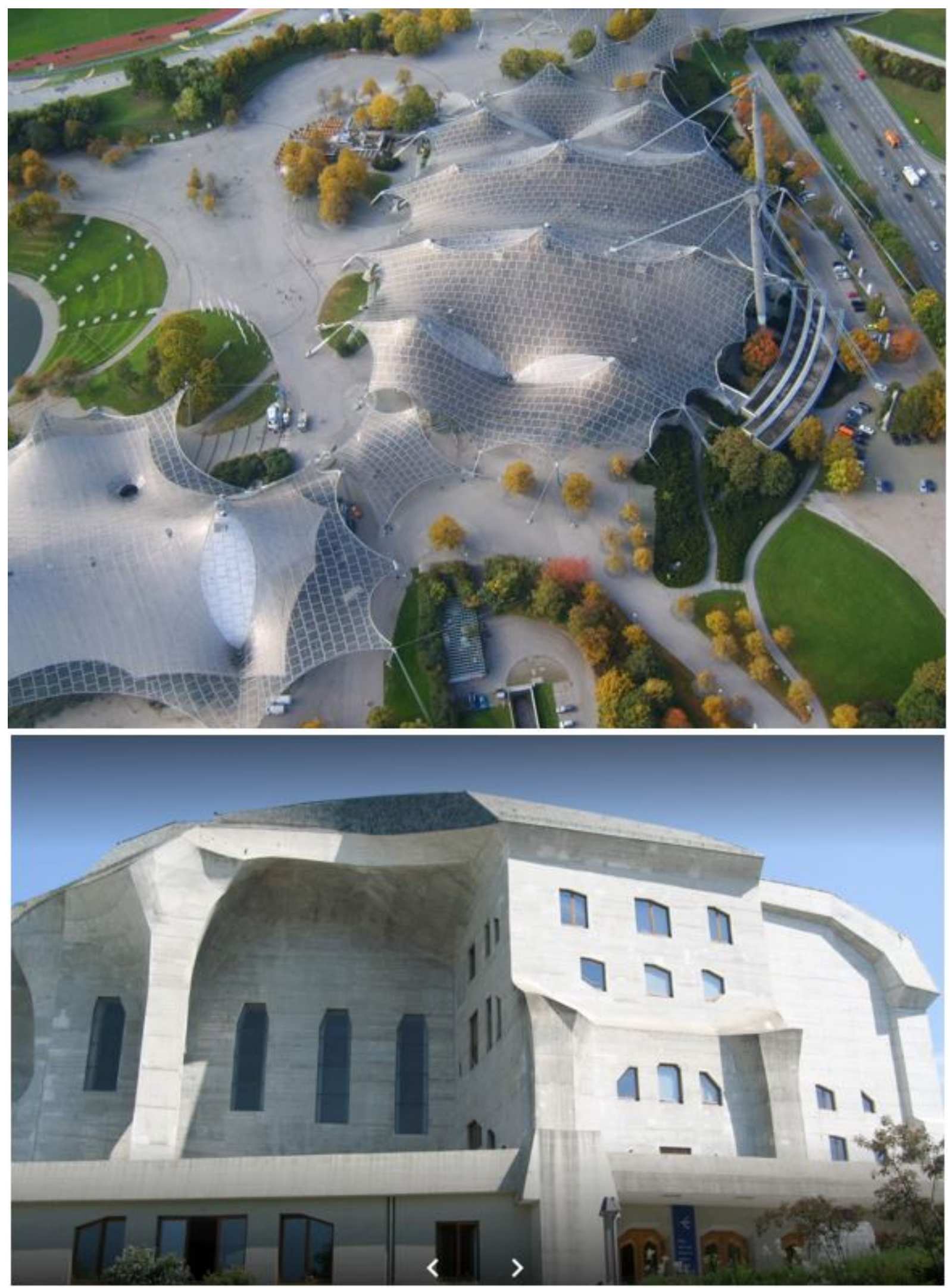

Figure 8: The Olympia Park and the Goetheanum as examples of 3D tensile and reinforced concrete structures. 
With over over 100 pages, one witnesses here in Chapter 10 how it became possible to build innovative structures, whose design benefit from the various theoretical insights earlier presented. Not only that, this chapter gives an opportunity for the author to present and discuss further the triad of industry, government and science, as summarized in Figure 9.

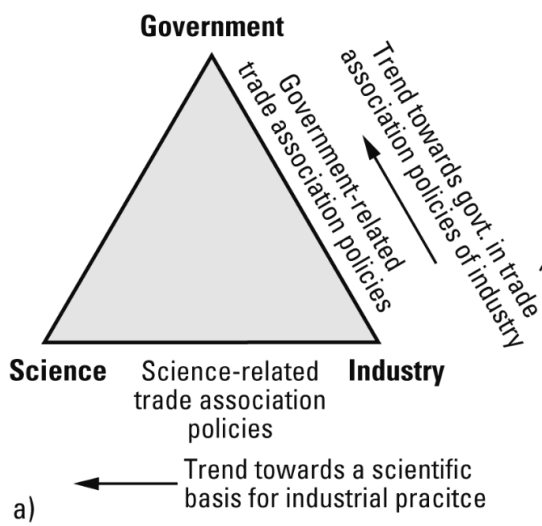

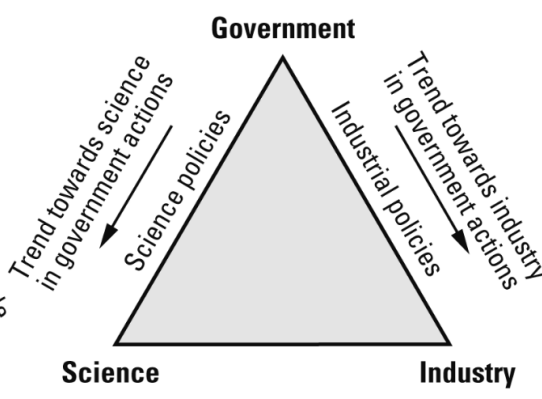

Science

b)

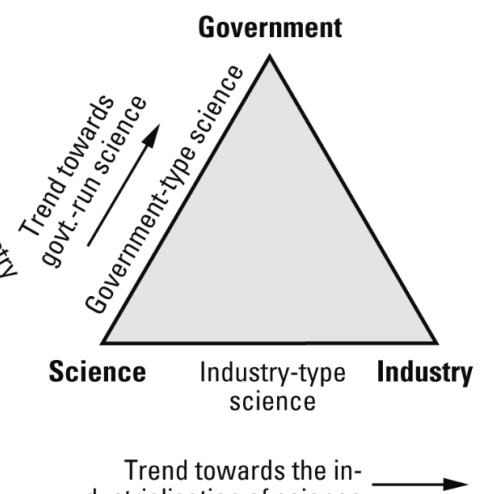

c) dustrialisation of science

Figure 9: Triad of Industry, Government and Science from different points of view.

In Chapter 11, The Consolidation Period of the Theory of Structures, which goes from 1900 to 1950, the author states that "the rationalisation movement in theory of structures and the establishment of the matrix concept can be regarded as the prelude to computational mechanics". Prof. Kurrer praises here a set of figures and diagrams that, so to say, diggest the heavy algebra involved in the analyses presented in the early evolutionary period. Many comments are also offered to the reader on the elastic plate theory, with the theory being completed by Sophie Germain (17761831) and Joseph Louis Lagrange (1736-1813). The author here skips an important point that Sophie Germain is, obviously, a woman, a rare fact in the whole history of engineering. Another woman also cited in this book, by coincidence also in this Chapter 11, is Sybille Krämer, whose "philosophical writings on the history of the prescriptive use of symbols in mathematics and logic formed the starting point for a rethink of the history of theory of structures."

In this chapter it is also presented the interesting Figure 10, which gives an overview of the various principles underlying the analyses of structures. 


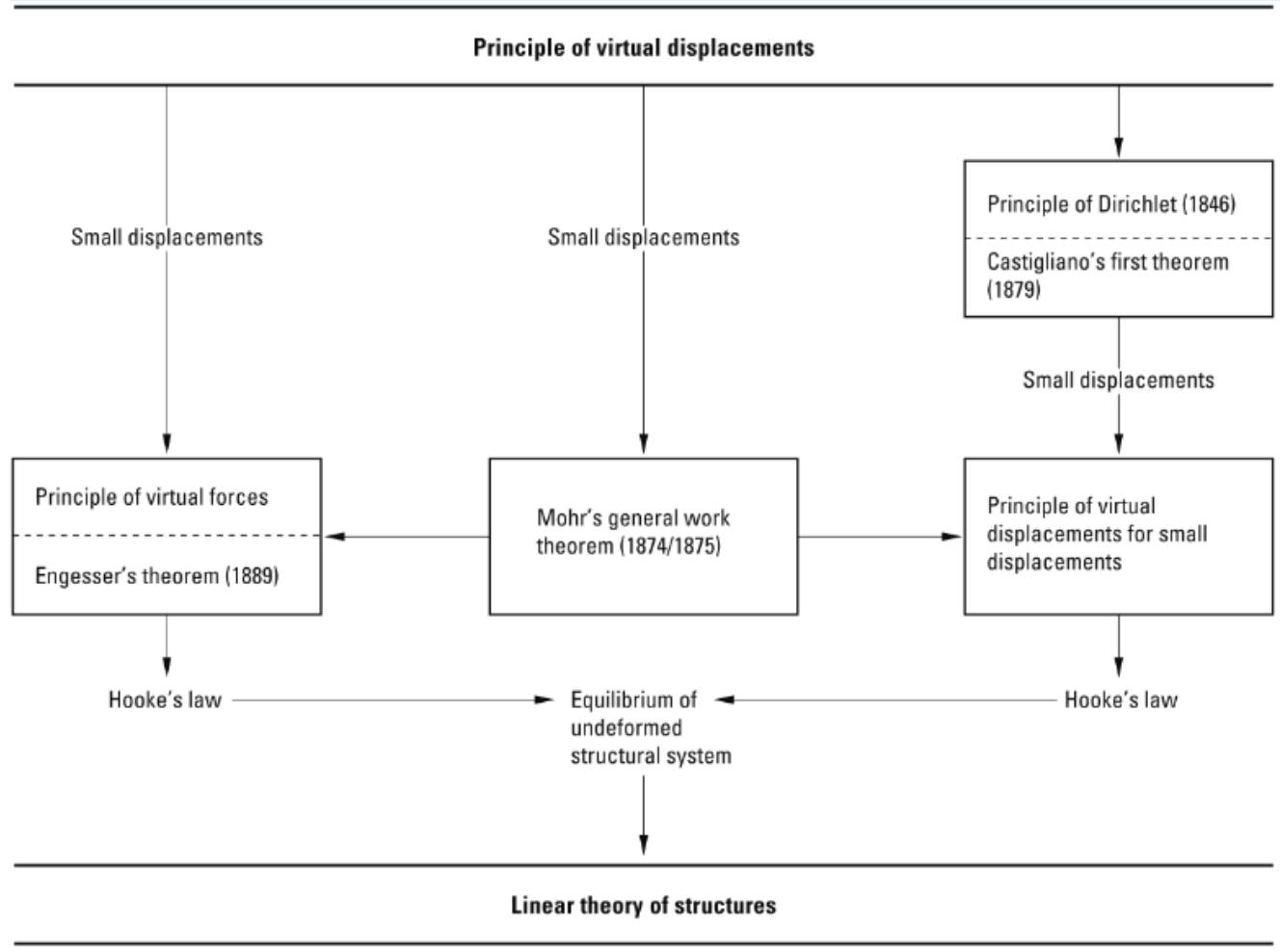

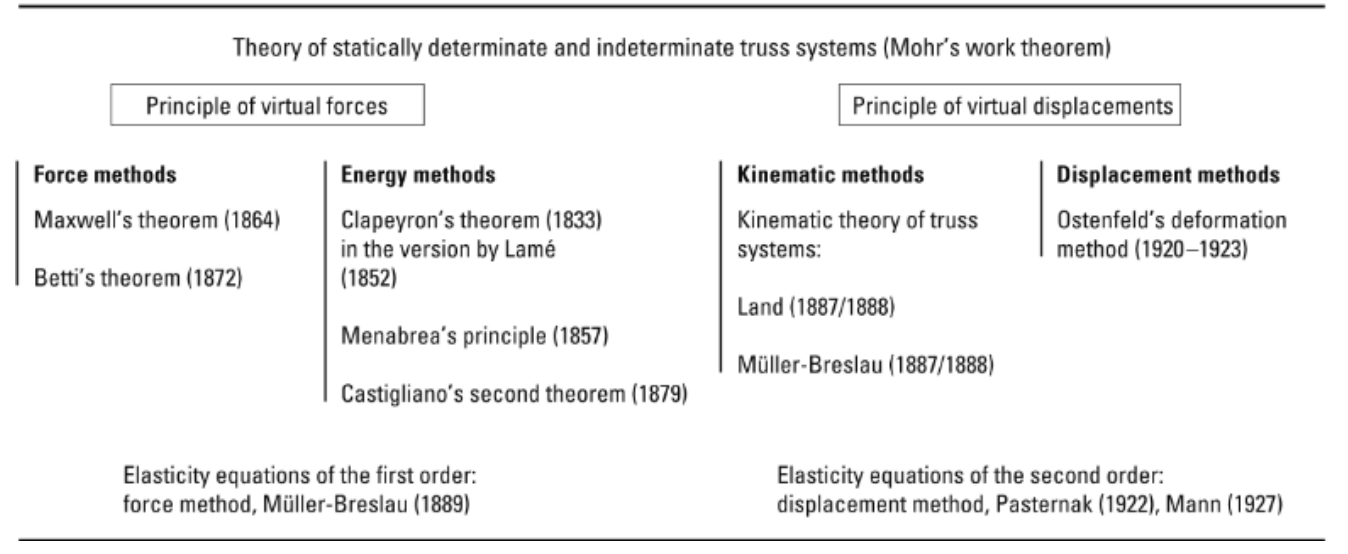

Figure 10: An overview of the method of analyses.

The steps towards a computing plan for the calculation of structures is very interesting, as one sees by delving in this Chapter 11. It was based also on matrix formulation calculation. The first ideas of using matrices in structural analysis were expressed by Edward Study (1862-1930) and this leads one to Chapter 12, The development and establishment of computational statics, where we hear Argyris stating that the "computer shapes the theory" and we see the author stating "today, numerical simulation, theory and experimentation are the three supporting pillars of computational mechanics in particular. Simulation in computational mechanics represents a new type of communication between theory and experimentation". This is set in a single Figure 11, to which I would add, as a complement, Figure 12. There one sees a mirrored triad of analysis-modelling-synthesis, which resembles the SabotGalbraith triad of estate-science \& technology \& productive sector. Indeed, the formation of young engineers is here viewed as including synthesis, apart of modelling and analyses. It is here in Chapter 12 that the Finite Element Method is presented, and as the most important intellectual technology of the second half of the 20th century. 


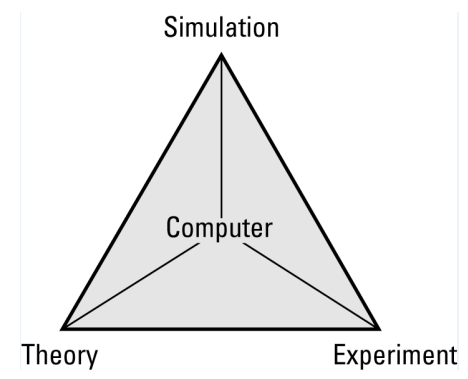

Figure 11: A tetrahedron of the main fields in structural design.
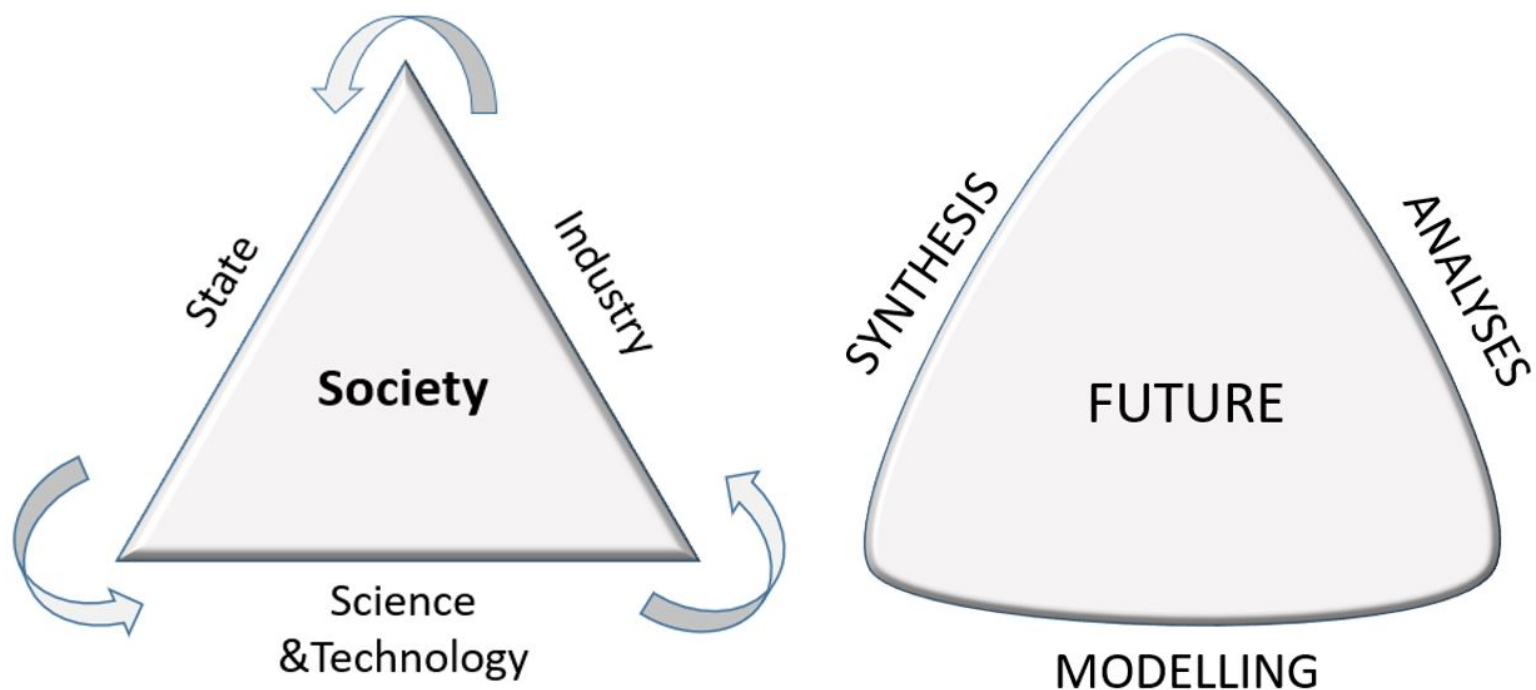

Figure 12: An evolving triad towards an equilibrium in the education of engineers.

Chapter 13, Thirteen controversies in mechanics of theory of structures, starts with the concept of force but it does not go deep enough on this fundamental topic. Chapter 14, Perspectives for a historical theory of structures, sees the struggle of the author with his "difficulties with the current reduction of the computational activities of the structural engineer to the mere manipulation of symbols". He attempts to "create an inherent aesthetic value for structural calculation". This effort goes in many ways but I believe the author succeeded perhaps because he equipped himself, via history, with a deep conception of engineering, reaching his, presumably, desire of bringing beauty, creativity, reflexion and ethics to centre of structural engineering.

The energy of the author is clearly seen in the closing of the book, where one would expect a sort of a summary of all that had seen previously. Instead, it is breathtaking to go along the 260 biographies of the protagonists of the theory of structures. There one can have an overview of the giants of Structure and Strength of Materials. As Ramm states in the Preface, this book is a "magnum opus" that can serve the next generations, helping them to appreciate all the phenomenal effort behind what has been designed and constructed in our society. The drawing of E. Benvenuto opening Chapter 1 of this book, repeated in Figure 13, may give a flavour of many aspects of structural analysis and of The History of the Theory of Structures: Searching for Equilibrium. I would highly recommend this book for all those interested in give meaning to what was said in the opening of this text: history puts knowledge in perspective. 


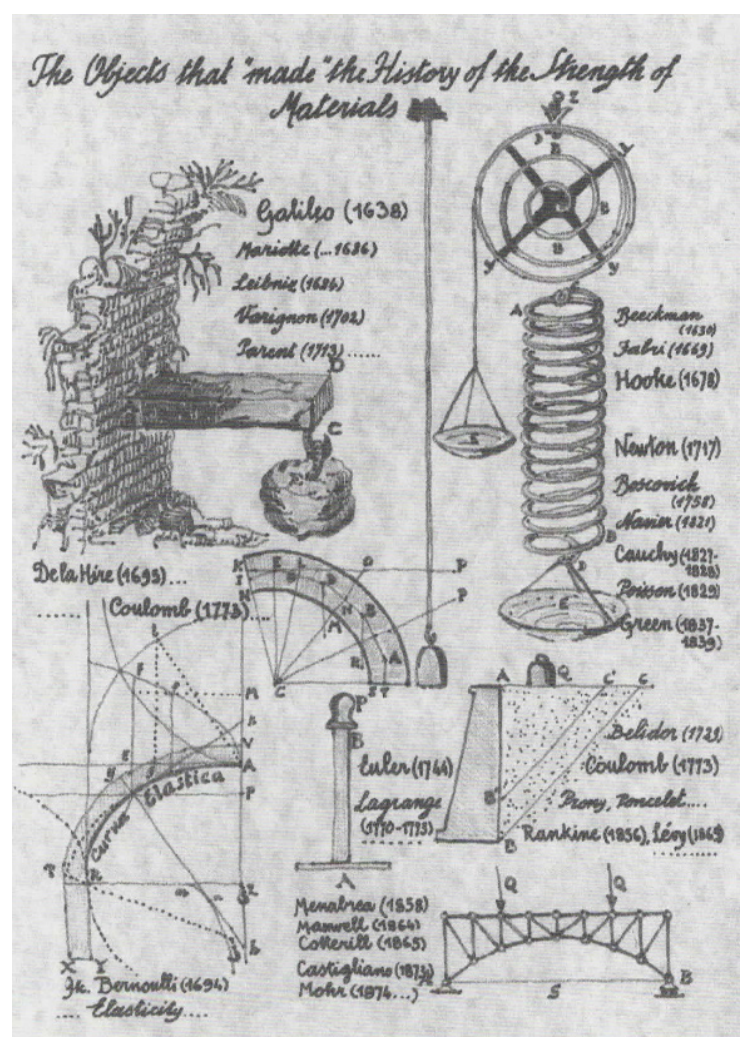

Figure 13: The objects that made the History of Strength of Materials (by E. Benvenuto).

\section{References}

Karl-Eugen Kurrer, The history of the theory of structures: searching for equilibrium, 2nd edition, Wiley, Ernst \& Sohn 2018, English translation by Philip Thrift.

H. Carvalho, R.H. Fakury, P.M.L. Vilela, The Challenges of Rehabilitating the Hercilio Luz Suspension Bridge, Latin American Journal of Solids and Structures 14 (2017) 700-713.

M. Alves, Impact Engineering: Fundamentals, Experiments, Nonlinear Finite Elements, Draft, www.impactbook.org, 2018. Leonardo da Vinci, I Libri di Meccanica, nellan ricostruzione ordinata di Arturo Ucelli, Editora Ulrico Hopli, 1939. 